\title{
Cotidiano escolar: análises de práticas
}

\section{Resumo}

O presente texto faz parte da minha dissertação de Mestrado em Políticas Públicas e Formação Humana (PPFH - UERJ): "Microfísica da Escola: o cotidiano em análise". Coloca em análise as vivências de professores, alunos, pais e demais participantes da comunidade escolar, tendo como objetivo problematizar os sentidos das práticas presentes na escola. Esta análise é feita através das escutas instituintes, da observação do que se passa à margem da história dita oficial, do que se move nas sombras dos acontecimentos, nos descentramentos. São utilizados analisadores, que são questões potentes dos relatos, havendo um diálogo entre saberes que possibilita a produção de resistências e linhas de fuga numa invenção de outras práticas.

Palavras-chave: Indisciplina; Cotidiano escolar; Biopoder; Assujeitamento; Resistência.

\section{Para citar este artigo:}

FERNANDES, Ângela Maria Gomes Ribeiro. Cotidiano escolar: análises de práticas. Revista Linhas. Florianópolis, v. 16, n. 31, p. $202-215$, maio/ago. 2015.

\section{Ângela Maria Gomes Ribeiro Fernandes \\ Mestre em Políticas Públicas e Formação Humana pela Universidade do Estado do Rio de Janeiro - UERJ - Brasil angelafernandes606@yahoo.com.br}




\title{
School Routine: analysis of practices
}

\begin{abstract}
The following text is part of my essay on Public Politics post graduation and Human Formation ( PPFH- UERJ) " Microphysics of schooling: everyday life in analysis". As an analysis of the experiences of teachers, students, parents and also other participants in the school community aiming to discuss the meaning of practices present at schools. This analysis is done through organized listening and also through observation on what happens the sidelines of the official history , which happens underneath of the events, and decentering. Analysers are used, which are powerful questions from reports, having a dialogue between knowledge that enables the production of resistors and a escaping line in an invention of other practices.
\end{abstract}

Keywords: Indiscipline; School rotine; Biopower; Subjugation; Resistance. 


\section{Considerações iniciais}

Trazendo para este texto análises de algumas das vivências experienciadas por mim nos mais de quarenta anos de magistério, pretendo dar ouvido às vozes que ressoam no burburinho da lembrança, a partir não das formas já constituídas, dos lugares e limites já definidos, mas DA MARGEM, possibilitando acessar as lógicas contidas nas relações, desterritorializando o lócus oficial que produz o sentido de centro, não esquecendo o que nos diz Deleuze (1993, p. 11): “escrever é um caso de devir, sempre inacabado, sempre em vias de se fazer... É um processo, ou seja, uma passagem de vida que atravessa o vivível e o vivido"

Leila Domingues Machado (2004) complementa:

(...) é o próprio corpo daquele que ao ser percorrido pelas leituras se apossou delas e faz sua afirmativa. A escrita pode transformar a coisa vista ou ouvida em batalhas. Ela transforma-se em um princípio de ação. Em contrapartida, aquele que escreve se transmuta em meio a esse emaranhado. (MACHADO, 2004, p. 149)

Foucault (2006) nos alenta quando, em seu discurso, dá importância a esses acontecimentos que passam à margem, despercebidos ou desqualificados na história oficial, que acontece ENTRE, como a costurar margens, desses saberes que em vozes querem calar. Com a palavra o filósofo:

(...) Basta que elas existam e que tenham contra elas tudo o que se obstina em fazê-las calar, para que faça sentido escutá-las e buscar o que elas querem dizer. (...) é por existirem tais vozes que o tempo dos homens não tem a forma da evolução, mas justamente a da "história". (FOUCAULT, 2006, p. 80)

Para o relato das minhas vivências com os "personagens" que dão vida às minhas histórias, pretendo discorrer na perspectiva da microfísica das relações. 
Vou me utilizar de falas como ferramentas analisadoras, pois os analisadores podem problematizar o não-dito institucional, interrogando a construção dos discursos e as condições de sua produção (LOURAU, 1993).

Pretendo, portanto, dialogar com as experiências instituintes que segundo Linhares (2004)

se afirma como uma experiência comum, partilhada por um grupo, contrapondo-se desta forma a experiência pontual e fragmentada do sujeito isolado de seus pares. Ê uma experiência aberta, não se afirma como "símbolo", com um significado unilateral, mas como "alegoria" por seus múltiplos sentidos e leituras. Podemos ainda articular este conceito ao sentido de "origem" em Benjamin, pois o instituinte na perspectiva de nossa pesquisa, não se confunde com o "novo", mas sim ê uma busca constante do movimento emancipador, movimento este que articula passado, presente e futuro. Contrapondo-se ao modismo e a uma reprodução estática do passado, a experiência instituinte sinaliza a densidade da experiência humana ao rememorar, recuperando, assim, o sentido de uma memória viva, pulsante onde o olhar para o passado potencializa o presente e nos ajuda na construção dos projetos de futuro, pois que ê ancorada em uma memória que ê capaz de prometer. (site: http://www.revistaaleph.com/home)

\section{Poderes paralelos, práticas de silenciamento e de confinamento}

Quando gerenciei a retomada da proposta pedagógica dos CIEP's na década de 1990, presenciei um "acordo" mórbido entre a escola e os xerifes das comunidades. Não só para garantir o acesso dos profissionais de educação e de saúde à escola, como para preservar a integridade física também dos prédios, de seu acervo e da merenda. Assisti a relatos de diretores, que ao ter o CIEP roubado foram se queixar aos "líderes" da comunidade e tiveram o produto do roubo devolvido, mas também encontraram, no dia seguinte, ao chegarem à escola, dois corpos de jovens jogados em uma vala. Esses corpos colocados em frente à escola era uma forma de intimidar outros roubos à unidade. Para esse poder paralelo, essa é uma ação preventiva de novas possibilidades de roubo, um recado para os moradores da comunidade. 
O silêncio da Secretaria de Educação me era passado assim: "estas questões internas da escola são mais bem resolvidas no âmbito escolar, o poder público não pode tomar conhecimento porque estaria admitindo sua ineficiência". Mas seu silêncio não seria uma estratégia política? Na verdade é admitir a falência do Estado em lidar com os jovens, esses meninos que foram resvalados para o tráfico, advindos da pobreza, num contexto de crise das políticas públicas. Poderia esta ser uma lógica burguesa?

Como essas crianças e jovens desta comunidade veem essas relações da escola com as milícias, a polícia e os xerifes ditos líderes das comunidades? Como introjetam a autoridade destes interlocutores? Onde está o poder público que se "omite" nestas comunidades, abandonando milhares de famílias à própria sorte, entre as milícias e os xerifes? Esta estratégica prática de “omissão" faz parte da própria gestão pública para os ditos mais pobres. Trata-se de códigos de conduta estabelecidos em uma comunidade, com normas e regras próprias: códigos de vida e de morte.

Este silêncio lido em medo, que não me parece normalizado, mas tensionado, me faz lembrar que o que interessa aqui é a construção de estratégias que não apenas contestem arranjos estruturais endurecidos e injustos, mas que também examinem nossa cumplicidade nesses arranjos. E a análise de nossa cumplicidade nos silenciamentos nos leva enquanto cartógrafos a nos implicar com a luta por manter a dobra flexível, distensionando e provocando possibilidades de pensar linhas de fuga.

Foucault (2002) relata que desde o século XIX uma tecnologia de poder, diferente, mas não substituta do poder soberano que fazia morrer e deixava viver, emergiu e ele a denominou de biopoder, que faz viver e deixa morrer. Essa tecnologia tem o poder de prolongar vidas com a promoção da morte, seu mecanismo fundamental é o racismo. Segundo Foucault o racismo tem como primeira função:

(...) estabelecer uma censura que será do tipo biológico no interior de um domínio considerado como sendo precisamente um domínio biológico. Isso vai permitir ao poder tratar uma população como uma mistura de raças ou, mais exatamente, tratar a espécie, subdividir a espécie de que ele se incumbiu em subgrupos que serão, precisamente, raças. Essa é a primeira função do racismo: fragmentar, fazer censuras no interior desse contínuo biológico a que se dirige o biopoder. (FOUCAULT, 2002, p. 304, 305) 
Um racismo que tem como lógica a máxima de que se você quer viver, precisa aceitar que o outro morra, como se para que o CIEP possa viver com "segurança", para que a "comunidade escolar tenha paz", tenha sido necessário extirpar o "mal" e o "mal” eram jovens da comunidade que roubaram a escola.

Esse poder sobre o corpo, sobre a vida, aparentemente naturalizado pela comunidade após tantos silenciamentos. Essa lógica que captura uma comunidade que vive entre milícias e "xerifes" e, apesar de tanta violência e sofrimento, opta pelo lado daquele que está mais próximo e obedece as normas e comandos desse poder paralelo. Paralelo enquanto poder que coexiste com o estabelecido, disputa espaços, funciona semelhante ao Estado com suas normas, leis e tribunais. Poder que seduz a tantos meninos, onde o respeito passa pelo calibre do revólver empunhado, sabendo que estão impondo à comunidade um sentimento que até há bem pouco tempo os acompanhou: medo, numa conta alta demais a ser paga muito em breve: as suas vidas. E mesmo sendo dia de tristeza para os pais daqueles meninos, é dia de "alívio" em nome de uma comunidade "mais sadia e pura", como nos diz Foucault:

A morte do outro não é simplesmente a minha vida, na medida em que seria minha segurança pessoal; a morte do outro, a morte da raça ruim, da raça inferior (ou do degenerado, ou do anormal), é o que vai deixar a vida em geral mais sadia; mais sadia e mais pura. (FOUCAULT, 2002, p. 305)

E a mesma comunidade que desce ao asfalto em protesto quando seus filhos são vítimas de balas perdidas ou de emboscadas policiais, que clama por justiça e paz em cartazes feitos a mão e empunhados nos cemitérios da vida, que na verdade podem ser traduzidos por vingança e extermínio, passa pelos corpos atirados na vala em frente à escola, confinada na "sorte" de estar viva. Comunidade abandonada por um poder público que a usurpa de direitos. Escola solitária, único braço do Estado em meio a um turbilhão incessante de regras e normas intra e extramuros. Escola possibilidade de construção coletiva de vida, de outras práticas, de alternativas para esses meninos e meninas. 
Esses filmes de vida que não me abandonam, esses flashes de tantas histórias e vivências, esses rostos que passam em galerias infindáveis, esse confinamento institucionalizado e eis mais um instante de reflexão...

A energia deles - meninos e meninas que brincavam de soltar pipa, jogavam futebol no campinho ao lado de uma lixeira a céu aberto, brincavam de gude e de pião, corriam equilibrando uma roda que acionavam com uma vareta, brincavam de rolimã contida entre quatro paredes, em carteiras perfiladas. Esse espaço de confinamento diário, obrigatório, ‘lócus' onde os corpos dóceis rebelam-se numa sabedoria construída; onde os regimentos e manuais ditam normas e regras necessárias à produção desses corpos obedientes, mas como nem todos os alunos aceitam essa asfixia em doses homeopáticas, essas mesmas normas e regras alavancam a construção da resistência.

Conversar com a realidade, com os diversos saberes que povoam a sala de aula, dialogar com textos que nos relatam outras falas subalternas, refletir sobre a organização secular desta instituição escola, nos propicia outro olhar, sobre as mesmas práticas do cotidiano de trabalho.

Havia um menino que não queria ficar em sala de aula e vivia pulando o muro da sala, pois no CIEP as paredes das salas que dão para o corredor são baixas. O professor de educação física gostava dele, dizia que ele participava das atividades e liderava o grupo. Esse menino falou sobre a Folia de Reis e pediu um espaço no CIEP para ensaiar uma apresentação. Formaram um grupo e numa das festas, sentados na arquibancada, escutamos a batida dos tambores da folia descendo a rampa. Uma batida tão forte que ritmou a batida de nossos corações. Ele à frente, conduzindo o espetáculo. Tendo tido suas habilidades reconhecidas pelo grupo de professores passou a frequentar a sala de aula, vitória! Porque a escola no momento em que abriu passagem para os tambores vibrarem gestou outra escola, possibilitando ao menino conseguir passagem para outras vibrações dentro dela, afirmando outra rede de saberes que não apenas aqueles prescritos como os próprios de aprendizagem.

Penso que o episódio contado acima nos apresenta um resultado de possibilidade cidadã. Entendendo a cidadania "enquanto conquista do espaço público, práticas éticas, onde as estratégias e a produção da realidade sócio-política é fruto de uma intervenção coletiva" (AGUIAR, ROCHA, 2003, p. 17). 


\section{Assujeitamento e desaprendizagens}

O assujeitamento é produzido por meio de uma série de práticas que interferem a ponto de criar algo, uma relação historicamente produzida e naturalizada na figura, por exemplo, do indisciplinado, delinquente, "uma coisa, uma coisa que, no entanto continuava a não existir" (FOUCAULT, 2008, p. 26-27).

O assujeitamento é um efeito de poder e, como tal, vai propiciando a produção de uma série de subjetividades.

A desaprendizagem é trazida a este texto como a desconstrução de um processo de aprendizagem contínua, de saberes, valores, concepções, sujeitos e invenção de outros.

Vejamos algumas desaprendizagens vivenciadas no CIEP: uma professora de alfabetização levou para a sala de aula uma folha de papel mimeografada, na qual os alunos deveriam descobrir o caminho certo que levasse o cachorrinho até sua casinha. Esta é uma prática recorrente até hoje. Os alunos, além de não realizarem a tarefa, rasgaram a folha, fizeram guerra de bolas de papel, deixando a professora extremamente irritada e frustrada. Nas reuniões diárias que tínhamos, ela perguntou: - Será que nenhum aluno tinha coordenação? O que havia acontecido? Na discussão coletiva, constatamos que a dúvida não cabia: os alunos tinham coordenação, iam de suas casas ao CIEP e retornavam, muitos sozinhos. Moravam num morro cheio de relevos e labirintos e não se perdiam. Começamos a problematizar: seriam o lápis e o papel, objetos que não eram de uso cotidiano em suas casas? Esse currículo oculto que a criança de classe média já traz para os bancos escolares? Será que a indisciplina não seria a recusa em colocar o cachorrinho na casinha? A recusa de que há um caminho certo para chegar à casa, que é preciso chegar à casa, que é preciso ser tutelado e guiado pelo outro?

Fizemos a experiência com as carteiras dos alunos primeiramente. Todos colocaram o cachorro na casinha. Nem todos o fizeram da forma convencional, seguindo o caminho traçado com os móveis, mas quem disse que só poderia haver um trajeto certo? Como não admitir a criatividade e não considerar maneiras diferentes de resolver problemas? Como rotular estas crianças de rebeldes, bagunceiras, descoordenadas ou 
desrespeitosas porque recusam uma atividade escolar? Quem desrespeitou quem? A professora, as crianças, o sistema educacional, as verdades construídas? Como descristalizar as formas de avaliação que só servem para fragmentar e hierarquizar?

Em que medida a escola de formação de professores teoriza metodologias e conceitos sem estar acompanhando de perto as práticas que constituímos diariamente, com seus saberes e suas verdades? Como esperar de uma escola de formação de professores, integralmente institucionalizada com suas regras, hierarquias funcionais, com seus saberes e práticas medidos milimetricamente por normas quantificadas, o espaço da escuta de outras práticas e saberes? Como produzir os deslocamentos necessários para desacomodar o olhar sobre os múltiplos acontecimentos que se precipitam em cascata no dia a dia de uma unidade escolar? Perceber muitas vezes saberes e verdades, perceptíveis a uma maneira de girar pelo deslocamento de quem observa, escondidos entre uma dobra e outra do acontecimento, é um desafio.

Havia a vantagem de estarmos num CIEP na década de 1980 e os professores terem, todos os dias, duas horas de discussão sobre suas práticas e poderem se interrogar sobre as formas de ação, podendo desmanchá-las. A vida na escola possibilita desaprendizagens, deslocamentos e invenções, que necessitam de uma prática de experienciação e problematização das formas de ação dadas. Talvez estivéssemos “focando o objeto" - a indisciplina -- quando na verdade deveríamos estar problematizando essa chancela, essa tutela, essa venda nos olhos que por vezes nos captura, mas que também em suas tensões provoca rupturas e possibilita novas ações. Essa é a riqueza desta nossa profissão de educadores que, como malabaristas, temos que capturar não a corda, que é o objeto, mas a cena, com seu público e flexibilizá-la, criar dobras e possibilidades de outras propostas, outras linhas, outros caminhos, outros programas que não necessariamente o dito oficial. É como a "alegoria do mirante", descrita por Löwy “a paisagem como painel não depende somente do observatório, mas também do próprio pintor, de sua forma de olhar e de sua arte de pintar" (LÖWY, 2007, p. 213).

Nos Conselhos de Classe do CIEP participavam todos os alunos e professores, direção, secretaria. Foram momentos de registros importantes entre falas emocionadas e propostas “iluminadas”, à luz da simplicidade e da técnica. 
Curioso observar que mesmo hoje, com todo o arcabouço da moderna pedagogia, fala-se em relações de troca de saberes entre ensinante e aprendente e conserva-se o nome aluno para designar o aprendente. A palavra "aluno" tem origem do latim, em que “a” corresponde a "ausente ou sem" e "luno", que deriva da palavra lumni, significa "luz". Portanto, aluno quer dizer sem luz, sem conhecimento. A ressignificação da palavra aluno tem sido motivo de muitos simpósios, congressos e temas de trabalhos de pesquisa, mas na concepção e nas práticas de grande parte dos educadores, essa relação dá-se ainda entre ensinante e aprendente, sendo o primeiro o professor e o segundo, invariavelmente, o aluno, numa prática de assujeitamento.

Considerando o aluno sem conhecimento e sem luz, desrespeitando sua cultura, por ignorá-la, considerando o saber propriedade de quem se formou nas escolas normais e universidades, esse intelectual professor só consegue aprender novas relações e estar aberto a novas experiências, se conseguir desconstruir o que para ele foi planejado pensar. Portanto, é urgente desaprender e isso só é possibilitado quando giramos o caleidoscópio procurando, deslocando, assuntando pistas entre os acontecimentos e suas sombras...

Dias (2008), referindo-se à análise de Rancière, nos dá a exata dimensão da diferença do método "faça como eu" e "faça comigo": no primeiro dizer, o aluno é refém do professor e no segundo caso o aluno busca a produção de novas práticas distintas das práticas de assujeitamento. "O aluno vê tudo por ele mesmo (...). E, assim, até o infinito. Mas esse infinito não é mais um segredo do mestre, é a marcha do aluno" (RANCIÈRE apud DIAS, 2008, p. 149).

Dias coloca em análise esta perspectiva e nos fala sobre a necessidade pedagógica de desaprender os métodos determinados aprioristicamente, ao afirmar a premência de se extrair "da própria formação toda a desaprendizagem que ela contém, sem formar para, mas co-formação forjando uma formação por vir" (Ibid., p. 146), apontando para um ensino entre, um espaço de interseção entre as formas instituídas.

Como bem interroga Dias, "que desafios se colocam entre professores, entre alunos, entre conhecer, entre políticas? Que práticas se constituem no movimento do ensino entre para que professores e alunos operem uma formação por vir?" (DIAS, 2008, p. 148-149). 
Nos Conselhos de Classe do CIEP que dirigi, um dos casos discutidos foi o de um menino de 10 anos, estigmatizado pela vizinhança, por sua mãe ser prostituta. Muitas outras mães não queriam esse menino na turma de suas filhas e seus filhos. $O$ menino tinha dificuldade de aprender, segundo relato de sua professora e agredia os colegas; morava na mesma comunidade que eles, mas viam a sua vida de forma preconceituosa, e ele percebia a rejeição. Havia também bate boca no portão da escola entre as mães sobre este caso. A situação tomou um vulto grande e as crianças trouxeram essa situação para dentro de sala de aula. Tínhamos que agir.

Ousamos fazer uma reunião com todos os envolvidos. Foi uma catarse. Fizemos outros encontros, com dinâmicas de grupo e textos para reflexão. Será que realmente conseguimos discutir as questões que os levaram a ter atitudes preconceituosas? Como os fizemos "aceitar" aquele menino e qual teria sido o sentimento que perpassou por muitos de nós? Pena? O menino foi menos agressivo, pensamos que tenha se sentido “protegido". Hoje me pergunto: quais teriam sido os sentimentos daquele menino que dizia tantos palavrões e, como já não os dissesse, avaliamos nossa vitória, pois ao moldálo, formatá-lo ao que considerávamos como a postura de um estudante, foi aceito. Tínhamos certezas e uma delas era que ele estaria sentindo-se mais feliz. Sob que prisma, que ótica? A nossa? E os colegas de fato o aceitaram ou o fizeram de maneira forçada? Como é sofrido se deslocar dentro das instituições formalmente constituídas, como é difícil passar por fora do que se produziu como uma instituição cristalizada para podermos lançar mão de - ou criar - outras tecnologias do poder. Quem sabe essas diárias reuniões coletivas do CIEP não nos fizeram reflexivos e pré-dispostos a observar com outros olhares? Quem sabe não conseguimos possibilitar a estes pais e ao coletivo de alunos envolvidos neste episódio outra forma de ver aquele menino? Quem sabe se aquele menino não sentiu essa transformação, já não era olhado da mesma maneira, já não era "o indesejável filho da prostituta”?

Sabe-se que grande parte do nosso coletivo de profissionais do CIEP não se deixou capturar por uma normalização, podíamos ter normalizado o episódio, já que também somos produção de uma sociedade de controle e atuamos profissionalmente nesta sociedade disciplinar, eivada de práticas ainda da sociedade senhorial, portanto, carregados com as tintas de "preconceitos", mergulhados na areia movediça de falsas 
pistas que nos conduzem muitas vezes a um campo de verdade produzido. Mas não, a recusa em adotar o objeto já pronto: o indesejável filho da prostituta produziu em nós um deslocamento.

Ratifico as ideias de Soares (2006) quando coloca que a capacidade de invenção é que torna o trabalho possível. Mesmo com os aprisionamentos, o trabalho escapa como a vida, e se torna micro-movimentos, inventivo e criativo.

Soares considera que

apostar na análise das situações reais de trabalho do professor, não é aqui, estratégia para a busca de um ideal, e sim para colocar em análise os processos formativos que estão em curso, contribuindo para novas formas de organização do trabalho. Um trabalho que seja inventivo, uma formação que viabilize o desencadeamento de processos de problematização que não se esgotem ao encontrar uma solução. (SOARES, 2006, p.9)

Alvarez-Uría e Varela (1992, p. 54) apontam que a escola é "uma autêntica invenção da burguesia para "civilizar" os filhos dos trabalhadores" Além de docilizar os corpos, de higienizar, de desqualificar, de introduzir na vida das famílias conceitos, padrões, metas que são suas, a escola também pretende "harmonizar" os conflitos, ideologizar relações e "construir" uma felicidade coletiva dentro de um contexto de verdades produzidas, longe da escuta dos saberes que pululam dentro de suas salas de aula e no seu entorno. Mas também é resistência. Por isso está se inventando e reinventando todos os dias.

Cabe a nós, trabalhadores da educação, estar sempre problematizando nossas práticas, inventando e reinventando nosso fazer, para que possamos perceber as capturas a que estamos suscetíveis e não precisemos nos amarrar ao mastro para não sermos capturados pelo "canto das sereias", tendo a atenção para não estarmos polemizando o que nos alerta Foucault ser bem diferente da problematização: "talvez seja preciso fazer um dia a longa história da polêmica como figura parasitária da discussão e obstáculo à busca da verdade" (FOUCAULT, 2006, p. 226), reconhecendo que 
o polemista se sustenta em uma legitimidade da qual seu adversário, por definição, está excluído. Problematizar não é polemizar. Pois, continua Foucault,

minha atitude não decorre dessa forma crítica que, a pretexto de um exame metódico, recusaria todas as soluções possíveis, exceto uma, que seria a boa. Ela é de preferência da ordem da "problematização": ou seja, da elaboração de um domínio de fatos, práticas e pensamentos (...). (FOUCAULT, 2006, p. 228)

\section{Referências}

AGUIAR, Kátia; ROCHA, Marisa Lopes da. Pesquisa-intervenção e a produção de novas análises. Psicologia Ciência e Profissão, Brasília, v. 23, n. 4, p.64-73, dez. 2003.

ALVAREZ-URÍA, Fernando; VARELA, Julia. Arqueología de la escuela. Madrid: La Piqueta, 1992.

DELEUZE, Gilles. Critique et clinique. Paris: Minuit, 1993.

DIAS, Rosimeri de Oliveira. Deslocamentos na formação de professores: aprendizagem de adultos, experiência e políticas cognitivas, 2008. 224 f. Tese (Doutorado em Psicologia) - Faculdade de Psicologia, Universidade Federal do Rio de Janeiro, Rio de Janeiro, 2008.

FOUCAULT, Michel. Em defesa da sociedade. São Paulo: M. Fontes, 2002.

FOUCAULT, Michel. Ética, sexualidade e política: ditos e escritos. 2. ed. Rio de Janeiro: Forense Universitária, 2006.

FOUCAULT, Michel. Nascimento da biopolítica : curso dado no Collège de France (1978 1979). São Paulo: M. Fontes, 2008. 
LINHARES, Célia. Experiências instituintes. 2004. Disponível em: <www//aleph.org.br> Acessado em: 28 maio 2012.

LOURAU, René. Análise institucional e práticas de pesquisa. Rio de Janeiro: UERJ, 1993.

LÖWY, Michael. Conclusão: as paisagens da verdade e a alegoria do mirante (para uma sociologia crítica do conhecimento). In: LÖWY, Michael. As aventuras de Karl Marx contra o Barão de Münchhausen: marxismo e positivismo na sociologia do conhecimento. São Paulo: Cortez, 2007.

MACHADO, Leila Domingues. 0 desafio ético da escrita. Rio de Janeiro: Psicologia \& Sociedade, n. esp., 2004.

SOARES, Auriseane Gomes. Construindo ferramentas para ir ao encontro dos saberes da experiência: novos olhares sobre a formação continuada. In:

SEMINÁRIO DA REDESTRADO, 6, 2006. Rio de Janeiro. Regulação educacional e trabalho docente. Rio de Janeiro: UERJ, 2006.

Recebido em: 23/03/2013 Aprovado em: 09/04/2014

Universidade do Estado de Santa Catarina - UDESC Programa de Pós-Graduação em Educação - PPGE Revista Linhas

Volume 16 - Número 31 - Ano 2015 revistalinhas@gmail.com 